\title{
Estado y modelo de desarrollo turístico en la costa Norte del Perú: El caso de Máncora, Piura
}

\author{
Fernando González Velarde* \\ Universidad de Las Palmas de Gran Canaria (España)
}

\begin{abstract}
Resumen: Este artículo explora los procesos de desarrollo turístico recientes liderados por la inversión privada y el mercado en la costa norte del Perú, a través del marco conceptual elaborado por los estudios sobre desarrollo y turismo sostenible. Se utiliza el caso del distrito de Máncora, Piura, para analizar las características de lo que el autor denomina el 'modelo turístico neoliberal peruano'. Luego, se examinan, desde una aproximación etnográfica multi-escalar, las tensiones y problemas que vienen ocurriendo como resultado de la implementación de dicho modelo en el distrito de Máncora. Finalmente, se exploran los cambios ocurridos en materia de política ambiental y los escasos intentos por modificar el modelo turístico actual. Con ello, se busca contribuir al debate sobre el turismo en la región andina, pero sobre todo, se resalta la urgente necesidad de cambiar el rol del Estado en el desarrollo de los destinos a fin de asegurar la sostenibilidad del turismo en el Perú.
\end{abstract}

Palabras Claves: Turismo Costero, Norte del Perú, Modelo de Desarrollo Turístico, Máncora, Invasiones de Tierra, Neoliberalismo, Turismo Sostenible.

\section{State and model of tourism development in Northern Peru: The case of Mancora, Piura}

Abstract: This article explores recent processes of tourism development led by the private sector and the market in the North coast of Peru. Based on the case of Mancora, Piura, the author analyses "Peru's neoliberal model of tourism development", which has been implemented in the last few decades. Next, the author moves on to examining, through an ethnographic approach, the tensions and problems brought about by the implementation of this model in Mancora. Finally, the author looks at the recent efforts aimed at implementing an environmental policy agenda in Peru and the still insufficient attempts at changing the current model of tourism development. The author concludes that the role of the state in developing local destinations should be urgently transformed in order to assure the sustainability of tourism in Peru.

Keywords: Coastal Tourism, Northern Peru, Model of Tourism Development, Mancora, Land Invasions, Neoliberalism, Sustainable Tourism.

\section{Introducción}

El Perú está posicionado como un país que promueve predominantemente el turismo cultural. Este tipo de turismo, "donde la herencia cultural, tanto del pasado como del presente, es central" (Baud y Ypeij, 2009: 4, traducción del autor), ha permitido que el turismo sea la tercera industria que genera mayores divisas a la economía nacional (Sariego y García, 2008). Frente a los alentadores resultados económicos vistos últimamente ${ }^{1}$, un creciente número de inversionistas turísticos y pobladores locales vienen desarrollando nuevos destinos que les permitan participar del boom turístico peruano. Por ello, las caletas de pescadores de la costa norte del Perú se han conceptualizado como el lugar ideal para acondicionar destinos de playa que satisfagan las necesidades de los mercados turísticos nacionales e internacionales (Viceministerio de Turismo-Mincetur, 2009). Asimismo, al convertir estas zonas rurales costeras en destinos de ocio, diversión, gastronomía, playa, naturaleza y deportes acuáticos, se

Licenciado en Antropología por la Pontificia Universidad Católica del Perú y doctor en Estudios Latinoamericanos por la Universidad de Newcastle, Reino Unido; E-mail: fgonzalezvelarde@gmail.com 
busca diversificar la demanda turística concentrada en la ciudad del Cusco y Machu Picchu, ofreciendo nuevos destinos y tipos de turismo. De este modo, la élite empresarial nacional, junto con los gobiernos neoliberales de los últimos años, esperan que el turismo se convierta en la segunda industria más importante del país y logre así consolidarse como eje impulsador de progreso socioeconómico y fuente fundamental de empleo (El Comercio, 2012).

Situado entre Los Órganos y Canoas de Punta Sal, el distrito de Máncora² (ver figura 1) se caracteriza por ser el destino de playa con la mayor cantidad de infraestructura turística en la costa norte del Perú, y es reconocido nacional e internacionalmente por sus playas y su clima tropical, por su gastronomía y su vida nocturna y por la práctica de deportes acuáticos. Los hoteles, restaurantes y casas residenciales construidas a lo largo de la franja costera del distrito, las mismas que vienen expandiéndose mas por la demanda turística que por una planificación sostenible del turismo a largo plazo, combinan materiales rústicos que se esconden bajo una capa de palmeras, sembradas en este territorio árido a fin de dar una identidad tropical. Las características del mar de Máncora han permitido que sea identificado como un destino idóneo para la práctica del surf. Asimismo, su biodiversidad marina ha abierto circuitos turísticos complementarios que fomentan el avistamiento de ballenas y tortugas, al igual que otros deportes acuáticos tales como el submarinismo y la pesca de altura. Esta nueva identidad turística convive con una identidad pesquera local, reproducida por comunidades de pescadores artesanales que habitan este territorio desde épocas pre-coloniales, y que permitió que sea una de las caletas de pescadores más importantes durante la década de 1960 y 1970.

Figura 1. Mapa del Perú y del Proyecto Playas del Norte (Mincetur)

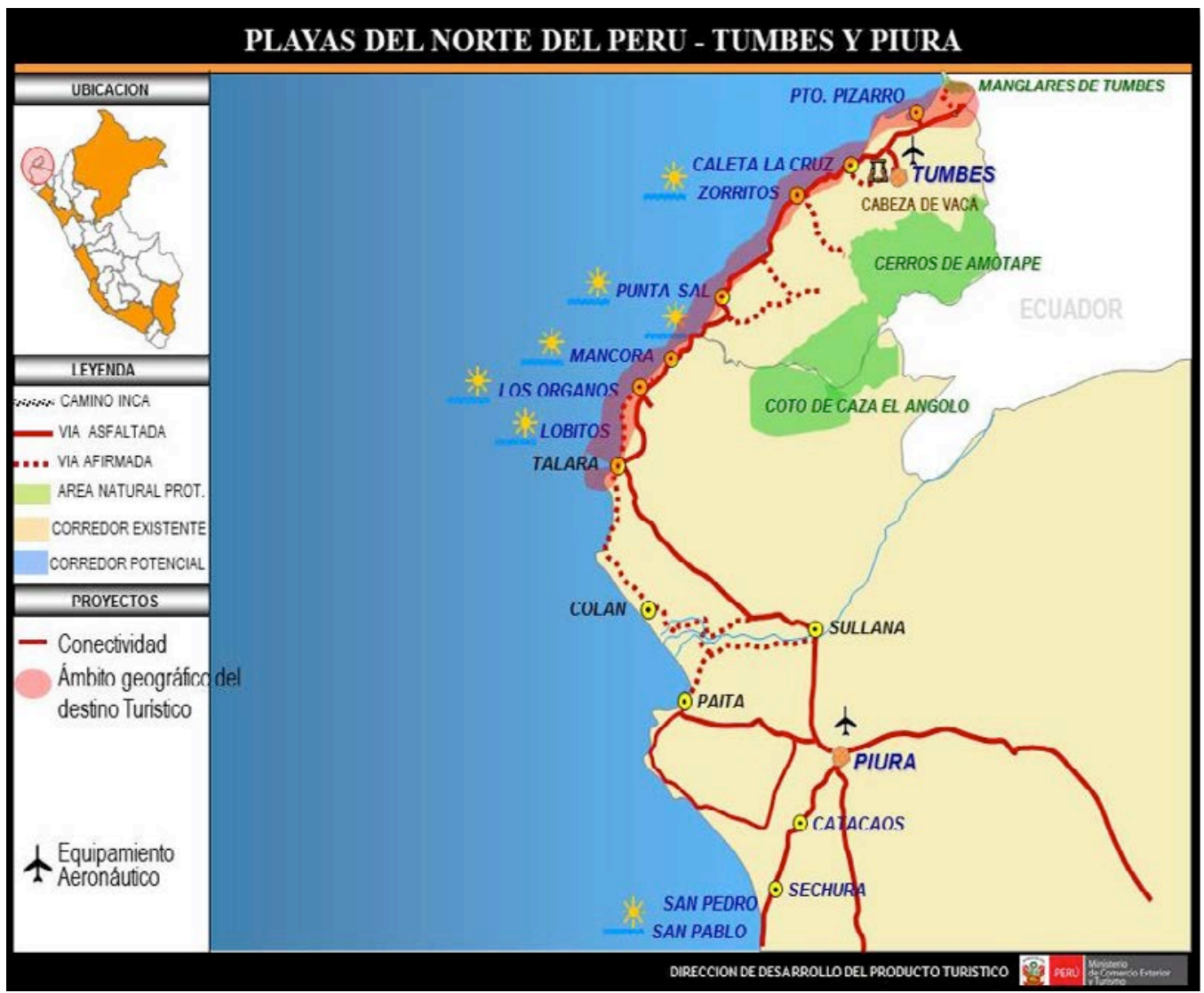


Con la carretera Panamericana Norte como vía de acceso principal, Máncora está ubicado en el kilómetro 1,165 al norte de Lima, la capital del Perú, y a solo 120 kilómetros al sur de la frontera que divide al Perú del Ecuador, haciéndola de muy fácil acceso para distintos mercados. Máncora recibe turistas nacionales que llegan de la capital, Lima, pero también de otras provincias cercanas tales como Piura, Trujillo y Tumbes. Los turistas extranjeros que visitan el distrito son diversos. Están aquellos que se encuentran viajando por Sudamérica y también están los que llegan a visitar Cuzco y deciden complementar su estadía con unos días de playa y descanso, antes de partir a su lugar de origen o seguir viajando por la región. Por su proximidad y fácil acceso, Máncora es un destino muy popular entre ecuatorianos que residen en las provincias del sur de Ecuador, y que llegan masivamente en épocas de carnavales. Máncora también es muy conocido entre deportistas brasileros que practican el surf; y, en los últimos años, se ha posicionado favorablemente en el mercado argentino y chileno como un destino de playa más económico en comparación a los que podrían encontrarse en estos países.

El proceso sociopolítico que transformó la caleta Máncora en uno de los principales destinos turísticos del Perú y de América del Sur comenzó a inicios de 1970. El turismo como actividad económica fue introducida desde fuera (Cohen, 1979) por parte de limeños de clase media y alta y con su progresiva incorporación como una actividad económica por parte de distintos sectores de la sociedad mancoreña. Este proceso de desarrollo local avanzó velozmente con el modelo turístico neoliberal implementado durante los años 1990, que fomentó políticas cuyo objetivo era incrementar agresivamente, y sin regulación, el número de turistas e inversionistas en los espacios locales. Como consecuencia, la industria turística viene experimentando un crecimiento dramático y excepcional; y la falta de planificación, de mecanismos reguladores y autoridades turísticas ambientales está trayendo severos y violentos problemas que amenazan la sostenibilidad ambiental y económica del turismo en Máncora.

El caso de Máncora nos permite analizar diversos aspectos del actual modelo de desarrollo turístico peruano, los problemas relacionados al uso de la tierra y las consecuencias ambientales que surgen como resultado de desarrollos turísticos ejecutados en contextos de reforma neoliberal. Para ello, utilizo el marco teórico elaborado por los autores que discuten el turismo sostenible y el desarrollo turístico (Butler, 1991, 1998, 1999; Briassoulis, 2002; Hunter, 1997; Saarinen, 2006), y analizo material etnográfico recolectado en diversos trabajos de campo realizados en Máncora, Piura y Lima durante los años 2007, 2010 y 2011. De este modo, exploro las características de lo que he denominado el 'modelo turístico neoliberal', mirando detenidamente las diferencias de poder entre políticas de promoción y desarrollo implementadas desde los años 1990 en adelante y explorando las ideas de límite de demanda que mantienen los principales actores turísticos del país. Luego, pasaré a examinar los problemas y tensiones que surgieron de desarrollos turísticos liderados por el mercado capitalista. Finalmente, analizaré los cambios ocurridos en materia de política ambiental y los aún escasos intentos por modificar un modelo turístico que amenaza la sostenibilidad del turismo en el Perú. De este modo, busco contribuir al debate que analiza los impactos del turismo en la región andina y en el Perú, y cuestionan el rol del turismo como una herramienta para el desarrollo sostenible (Baud and Ypeij, 2009; Carnaffan, 2010; Desforges, 2000; Fuller, 2010; García, 2015; Gascón, 2005; Raftoupolous, 2013; Ypiej and Zoomers, 2006; Zorn and Farthing, 2007).

\section{Características del Modelo Turístico en el Perú}

Los estudios sobre planificación turística sostienen que los destinos cuentan con un máximo número de turistas que tales destinos pueden recibir sin provocar alteraciones negativas al medio ambiente y a la sociedad, es por ello que la idea de 'límite' adquiere un protagonismo central en el debate sobre sostenibilidad turística (Butler, 1991, 1998, 1999; Saarinen, 2006). Los autores que contribuyen a esta discusión argumentan que una vez excedidos los niveles de capacidad de carga, el destino turístico experimenta cambios negativos y, por consiguiente, se vuelve menos atractivo. Asimismo, tales autores son claros al argumentar que el turismo provoca degradación ambiental y afecta negativamente a las poblaciones locales (Butler, 1999). Por ello, el crecimiento exponencial de la demanda de turistas en destinos que se han desarrollado sin planificación ni regulación va a incrementar inevitablemente la presión y demanda de recursos naturales, deteriorando así el recurso y amenazando la viabilidad del turismo (Butler, 1991). Entonces, poner límites al crecimiento de la demanda turística y dar preferencia a la planificación del desarrollo turístico son factores cruciales. 
El boom turístico peruano, que se inició durante los primeros años de la década de 2000, se llevó a cabo en un país con un gobierno que no tenía ni planes de desarrollo turístico definidos ni los mecanismos necesarios para controlar la rápida expansión de la industria durante este periodo. Este boom sucedió gracias a las estrategias que el sector privado y el sector público vienen implementando desde 1990 y que tienen como objetivo a corto plazo incrementar ilimitadamente los flujos de turistas nacionales y extranjeros y así expandir la industria por todo el territorio nacional. Tales estrategias y acciones vienen siendo justificadas y legitimadas con discursos que resaltan la importancia del turismo como herramienta para el desarrollo nacional y local, puesto que se le considera como un disparador del crecimiento económico; sin embargo, se ignoran las estrategias de control y límite que los planificadores turísticos recomiendan.

Desde el año 2007, con la obtención de recursos económicos por medio del "impuesto extraordinario para la promoción y desarrollo turístico" creado por la Ley N 27889 (Congreso de la República, 2002), promulgada por el ex presidente Alejandro Toledo, PromPerú ${ }^{3}$ viene implementando campañas de marketing que promuevan los destinos más importantes del país tanto en mercados extranjeros como nacionales. Asimismo, ha lanzado campañas que intentan crear consciencia sobre la importancia del turismo, buscando motivar a los peruanos de clase media y alta a viajar por el país. La puesta en práctica de estas estrategias ha incrementado exponencialmente el número de turistas nacionales y extranjeros y, tras ello, han evolucionado en estrategias mucho más especializadas, que intentan llegar a la amplia gama de sectores del mercado turístico nacional y, sobre todo, incrementar el tiempo de estadía de los turistas y la cantidad de dinero gastado en el destino (Sariego y García, 2008: 23). Además, PromPerú trabaja cercanamente con empresarios turísticos (dueños de hoteles, agencias de transporte y restaurantes) para lanzar promociones más accesibles que puedan alentar a una mayor cantidad de turistas a viajar durante las temporadas de baja ocupación ${ }^{4}$.

Como parte de este plan, PromPerú lanzó en 2009 una campaña publicitaria bajo el nombre 'Perú, vive la leyenda' que tenía como objetivo garantizar la sostenibilidad del turismo, haciendo que el Perú se convierta en un destino exclusivo para un mercado especializado. En este sentido, el público objetivo eran los turistas en búsqueda de experiencias tales como 'ecoturismo', 'turismo cultural', 'turismo de aventura', 'turismo deportivo' y 'gastronomía'; y también exploradores tras lugares que no hubieran sido tocados por la modernidad. Además, esta campaña procuró que los turistas piensen en el Perú como la mejor opción para visitar en su próximo viaje, que vuelvan a visitar el destino y que lo recomienden a sus parientes y amigos (PromPerú, 2009: 19-33).

Con esta estrategia se trató de cambiar el tipo de turista objetivo, solución comúnmente utilizada por los planificadores turísticos, quienes buscan que los ingresos generados por esta actividad no se vean afectados en el momento de reducir la demanda de visitantes (Butler, 1991: 204). Con esta estrategia se asume que menos turistas con mayor disponibilidad económica "producirían igual o mejores resultados económicos que el turismo masivo, y alterarían en menor medida el ambiente físico y social, por lo que [esta estrategia] representaría una forma de turismo sostenible" (Butler, 1991: 206; traducción del autor). Sin embargo, en el Perú existen importantes inconsistencias respecto al número de turistas que el país es capaz de recibir, las mismas que sugieren que estos esfuerzos están subordinados a los intereses individuales de la clase empresarial y de los últimos gobiernos neoliberales. En efecto, más allá de las estrategias que buscan cambiar el tipo de turista promedio, la expectativa de los últimos gobiernos es que el Perú debe atraer la mayor cantidad posible de turistas ${ }^{5}$. Esta posición es respaldada firmemente por la élite empresarial, cuyos miembros consideran que en el Perú no existen límites respecto a la cantidad de turistas que se pueden recibir ${ }^{6}$.

Siendo los principales actores sociales encargados de desarrollar la industria, los inversionistas turísticos buscan influenciar fuertemente cuando el Estado diseña sus políticas turísticas. Por medio de la Cámara Nacional de Turismo (Canatur), la élite empresarial viene solicitando desde hace varios años al Estado incrementar su participación en el directorio de PromPerú ${ }^{7}$, el cual decide cómo se utilizarán los fondos acumulados por el mencionado impuesto extraordinario. Este impuesto, mediante el cual cada persona que entra al país por vía aérea desde el extranjero tiene que pagar quince dólares americanos, en marzo de 2011 ya había acumulado alrededor de 45 millones de dólares, monto utilizado por el Fondo para la Promoción y Desarrollo Turístico Nacional para implementar proyectos enfocados en promocionar el país en el extranjero y también en aquellos que tengan como objetivo desarrollar infraestructura turística en el territorio nacional. Esto confirma que los miembros del sector privado buscan obtener mayor poder dentro del directorio de PromPerú con la finalidad de controlar los recursos 
económicos destinados para campañas publicitarias y proyectos turísticos en beneficio de los sectores dominantes de la industria turística.

Sumado al hecho de que la industria turística se desarrolla bajo un modelo donde la idea de límite está subordinada a los intereses de grupos económicos, en los años 1990, con la implementación de la reforma neoliberal, se restringió considerablemente el rol del Estado en lo que respecta a liderar el desarrollo turístico. Producto de recortes, el número de trabajadores del entonces Ministerio de Industria, Turismo, Integración y Negociaciones Internacionales (Mitinci) se redujo de 2,700 a 300. Algo similar ocurrió en la Dirección Nacional de Turismo ${ }^{8}$, donde el equipo de trabajo experimentó un recorte de alrededor de 210 funcionarios, disminuyendo de 270 a 60 personas (Desforges, 2000: 186). Asimismo, años después, a pesar de que PromPerú era una dependencia de la oficina ministerial del Ministerio de Comercio Exterior y Turismo (Mincetur), su directora recibió tanto poder como el de la viceministra, generando diferencias importantes entre PromPerú y el Viceministerio de Turismo ${ }^{9}$. Entonces, si durante dicho periodo este viceministerio tuvo un rol periférico, PromPerú adquirió un gran poder político y económico, lo cual generó tensiones y conflictos entre las agencias estatales responsables de la elaboración de planes conjuntos que incluyeran tanto la promoción como el desarrollo y regulación de destinos turísticos.

El desbalance de poder entre políticas de promoción y políticas de desarrollo también se manifiesta claramente en la repartición de los fondos para el desarrollo de la industria turística. En efecto, la manera como se destinan los recursos obtenidos a través del impuesto extraordinario para la promoción y desarrollo turístico resalta este desbalance, puesto que el $70 \%$ va a PromPerú para campañas promocionales y el 30\% restante se destina al Plan Copesco, el cual se ocupa de implementar infraestructura turística pública en el país. En este sentido, se invierte bastante en atraer turistas por medio de la promoción, pero muy poco en acondicionar y desarrollar destinos para que puedan ser visitados y en controlarlos para que se mantengan en el tiempo sin provocar impactos serios e irreversibles en el medio ambiente.

Finalmente, desde 2004, el ministro del Mincetur ha sido siempre un economista o un administrador empresarial especializado en dinámicas del mercado. Este bagaje empresarial que caracteriza a los especialistas que ocupan roles tan importantes para el turismo del país ha permitido que la industria esté gobernada por una conceptualización del turismo que se reduce a la relación entre oferta y demanda; en otras palabras, al número de turistas y al número de destinos turísticos disponibles para visitar. Priorizar las ganancias impide desarrollar una visión de un Estado que se considere a sí mismo como la entidad principal encargada de regular y gobernar la industria turística. Por ello, en los procesos por los cuales se han definido las políticas estatales, la sostenibilidad ambiental de la actividad ha sido, lamentablemente, puesta a un lado con la finalidad de permitir la generación de capital a través del incremento de visitantes.

\section{Desarrollo Turístico en Espacios Costeros: Conflictos, Invasiones y Problemas Ambientales}

Máncora atraviesa actualmente la etapa que el geógrafo Richard Butler (1980) denomina "de consolidación" (consolidation stage). Esto significa que gran parte de la población depende económicamente del turismo y por tanto existen crecientes esfuerzos de parte del sector privado y los gobiernos de turno para extender la temporada y el mercado turístico. En Máncora, desde la llegada de los primeros turistas e inversionistas limeños en la década de 1970, la infraestructura turística se ha expandido descontroladamente por toda la franja costera del distrito y ahora la mayoría de la población se encuentra directa o indirectamente vinculada al turismo. A pesar de que desde el Estado no se llevaron a cabo proyectos que acondicionaran los destinos locales, ello ocurrió gracias a que la implementación del modelo neoliberal de desarrollo turístico incrementó dramáticamente la cantidad de visitantes e inversionistas, favoreciendo un modelo sin límites de demanda y generando un desbalance entre políticas de promoción y de desarrollo turístico. Este modelo, que además redujo el rol regulador del Estado en todos los niveles de gobierno, también liberalizó los espacios locales a fin de fomentar las inversiones privadas y la explotación de los recursos naturales, perpetuando una relación colonial con el medio natural (Pálsson, 1996) ${ }^{10}$.

Durante la década de 1990, bajo el supuesto de que el mercado capitalista fomentaría un uso más eficiente de la tierra, los gobiernos de turno promulgaron una serie de leyes que buscaban eliminar las restricciones que protegían la transferencia de tierras en espacios locales con la finalidad de fomentar las inversiones y la exportación. Entre el paquete de leyes promulgadas desde 1991 hasta 1997 cuyo 
objetivo era liberalizar y facilitar la titulación de tierras de las comunidades campesinas de la costa, el Decreto Legislativo Nº53 (Congreso de la República, 1991) anuló la Reforma Agraria del presidente Juan Velasco Alvarado y la nueva Constitución neoliberal de 1993 eliminó las garantías proteccionistas otorgadas a las comunidades indígenas desde 1920. Finalmente, con la Ley de la inversión privada en el desarrollo de las actividades económicas en las tierras del territorio nacional y de las comunidades campesinas y nativas (Ley $\mathrm{N}^{\circ}$ 26505; Congreso de la República, 1995) y la Ley de titulación de comunidades campesinas de la costa (Ley $\mathrm{N}^{\circ} 26845$; Congreso de la República, 1997) se terminó por definir el proceso por medio del cual las comunidades campesinas podían transferir, vender o donar sus territorios y así participar del mercado de tierras.

De esta manera, los recursos naturales en zonas rurales fueron abiertos al mercado capitalista y a la industria turística, dejando a las autoridades locales la responsabilidad de planificar, controlar y regular la expansión de la infraestructura. El debate sobre la planificación del desarrollo turístico considera que las autoridades locales tienen un rol central en el control de la expansión de la infraestructura turística y en la limitación del número de visitantes; pero para ello se necesita que "exista un acuerdo con todos los niveles de gobierno y los ciudadanos" (Butler, 1991: 205; traducción propia). El caso de Máncora muestra todo lo contrario, ya que tanto el surgimiento y consolidación de estructuras de gobernanza de la tierra como la implementación de planes coordinados estuvieron siempre obstaculizados por un conflicto legal muy intenso por la propiedad de la tierra entre la Comunidad Campesina de Máncora, dueña del territorio, y la Municipalidad Distrital de Máncora.

Además, para el distrito de Máncora, la liberalización de la tierra fue social y ecológicamente perjudicial debido a que en este periodo la caleta de pescadores estaba recibiendo un gran flujo de turistas e inversionistas sin estar preparada para lidiar con lo que rápidamente se convirtió en un destino de turismo de playa masivo nacional e internacional, dado que no contaba con un sistema de planificación ni con un plan de desarrollo territorial que pudieran haber garantizado el manejo responsable de los recursos naturales. En efecto, las autoridades locales no tenían experiencia en gestionar destinos turísticos y tampoco contaban con la capacidad para proteger los recursos naturales de su distrito por falta de información, recursos y conocimiento ${ }^{11}$. Asimismo, este proceso fortaleció las diferencias y tensiones entre los grupos sociales que conviven en el lugar, permitiendo que se conceptualice de distintas maneras y que se lleven a cabo acciones para que cada uno de estos grupos concretice proyectos económicos y políticos individuales. Este contexto adverso permitió que se intensifique la apropiación ilegal de terrenos.

Catalogados como 'invasores de tierras' por miembros de asociaciones turísticas y ambientales y por inversionistas, algunos pobladores han sacado ventaja de la ausencia de estructuras de gobernanza de la tierra para apropiarse de la mayor cantidad posible de terrenos a fin de expandir sus negocios o fomentar un mercado ilegal para su venta. En efecto, en Máncora la invasión se ha convertido en un negocio muy lucrativo debido al incremento del valor de la tierra y las propiedades producto del auge del turismo. Por ello, en las últimas décadas el número de invasores se ha multiplicado a la par que una creciente cantidad de inversionistas que buscan comprar terrenos para participar de la industria turística, permitiendo todos ellos que este patrón de uso de recursos naturales y apropiación del lugar sea dominante en el desarrollo turístico de Máncora.

Los invasores son una combinación de mancoreños, trujillanos y piuranos que andan armados y actúan de forma violenta y que, en algunos casos, son miembros de pandillas familiares. Para las autoridades locales, regionales y nacionales, estos invasores están transformando a Máncora en 'tierra de nadie’ y cada vez es más común escuchar sobre asesinatos producto de peleas entre pandillas o por ajuste de cuentas. Es más, en agosto de 2014, el ex presidente de la Comunidad Campesina de Máncora, Everardo Távara Valladares, a quien entrevisté en varias oportunidades en los años 2010 y 2011, fue asesinado a balazos por sicarios (RPP, 2014), producto de un ajuste de cuentas que, según mis informantes, se debió a unos terrenos que Távara habría vendido siendo presidente de la comunidad.

Si bien algunos invaden terrenos con fines de especulación y venta, también hay otro tipo de poblador, el cual se apropia de un terreno con la finalidad de acondicionarlo para la venta de productos o de construir un hotel o restaurante, y así participar de la industria turística. Estos pobladores, también denominados invasores, cercan un pedazo de tierra, que puede incluir áreas públicas, durante la noche, luego ponen esteras y plantas para delimitar el área tomada y, conforme pasa el tiempo, construyen gradualmente el primer y segundo piso con materiales nobles. Muchos de ellos ahora tienen una buena cantidad de años viviendo en estos terrenos y han logrado consolidar negocios muy lucrativos.

A pesar de que invasores e inversionistas buscan formalizar sus propiedades solicitando a la municipalidad y al juez de paz una prueba de derecho de posesión, la única institución oficialmente encargada 
de definir sobre la propiedad de las tierras del lugar es la Comunidad Campesina de Máncora, puesto que ella es propietaria de la casi totalidad del territorio de Máncora producto de la Reforma Agraria realizada durante el gobierno de Juan Velasco Alvarado en 1969. Por esta razón, para formalizar sus terrenos, tanto los invasores como los inversionistas deben primero acercarse a la comunidad campesina, que se ha convertido en una especie de inmobiliaria, para luego ir a la municipalidad para inscribir sus propiedades. Este proceso ha traído graves problemas a la municipalidad distrital, ya que no tiene control de las ventas que la comunidad campesina realiza dentro del casco urbano y tampoco de los usos que se da a estos terrenos. Por ello, ha habido casos donde se acusa a la comunidad campesina de haber vendido desde terrenos en plazas públicas y lozas deportivas hasta una parte de la iglesia del distrito.

Este problema se agrava aun más con la actitud de búsqueda de lucro de gran parte de los directivos de la comunidad campesina, quienes no están interesados en encontrar soluciones a este crecimiento urbano desordenado. Ellos argumentan que, como dueños oficiales del territorio de Máncora, tienen todo el derecho de vender cualquier terreno que se encuentre dentro de su territorio, incluyendo áreas públicas y zonas vulnerables; al mismo tiempo, afirman que el control de la expansión urbana del distrito no es problema de la comunidad sino de la municipalidad, quien es la autoridad responsable de decidir dónde y qué se construirá ${ }^{12}$. En otras palabras, ellos pueden vender terrenos dentro de su territorio, pero no se responsabilizan por lo que se hará con ellos ni por lo que se construirá.

Frente a este contexto adverso, los agentes municipales sostienen que desde que la comunidad obtuvo el control oficial de la tierra, la autoridad de la Municipalidad Distrital de Máncora ha sido puesta en un segundo plano, generando así un vacío de poder en el distrito, lo que dificulta el control. Además, desde el surgimiento del turismo en su localidad, esta municipalidad ha estado completamente ausente respecto a la regulación de la tierra. Más que ser la autoridad local encargada de controlar el desarrollo turístico - definiendo los usos del espacio y otorgando o no licencias de funcionamiento-, el rol de la municipalidad ha estado limitado a emitir certificados de posesión para así poder incrementar sus rentas con el cobro de los impuestos prediales y arbitrios.

En una dimensión más técnica, el 'Plan de reordenamiento territorial de Máncora' -cuya función proyectada era definir qué zonas son las más adecuadas para desarrollar infraestructura turística, qué tipo de edificaciones se permiten y qué usos específicos se debe dar a la tierra en Máncora, tomó alrededor de cinco años en aprobarse. Este documento fue elaborado durante el segundo gobierno del alcalde Florencio Olibos, en 2006, y finalmente se aprobó en julio de 2011, cuando los invasores ya se habían apropiado de la mayoría de los terrenos que este documento buscaba regular y controlar. Además, la oficina municipal distrital de turismo actualmente no tienen a su cargo la planificación del desarrollo turístico en su localidad ni cuentan con las facultades para controlar o restringir el acceso a recursos naturales. Es más, ni siquiera está directamente relacionadas con las agencias municipales que velan por el desarrollo urbano del distrito y por la prevención de los desastres naturales, como el Instituto Nacional de Defensa Civil (Indeci).

En el caso de Máncora, la labor de planificación urbana y turística ha sido llevada a cabo por arquitectos que no se encuentran familiarizados con la dinámica espacial y turística del distrito, puesto que suelen ser profesionales de otros lugares. Además de lidiar con las necesidades que trae consigo la expansión urbana de un distrito, estos funcionarios municipales tienen que responder a las demandas que el turismo ocasiona en los espacios locales. Todo esto sucede en un país donde las municipalidades distritales tienden a considerar la planificación urbana como la administración de la tierra debido a la ausencia de políticas urbanas, lo que no permite a tales funcionarios que consideren el comportamiento espacial de la ciudad y su dinámica natural como elementos claves al diseñar el desarrollo urbano en sus localidades (Pineda-Zumaran, 2012).

En la actualidad, el territorio costero de Máncora está sujeto a una gran presión por parte de la industria turística. En efecto, el barrio llamado 'Centro Veraniego' viene siendo ocupado por hoteles, restaurantes y otros negocios. Además, entre enero y octubre de 2010, como parte del proyecto 'Playas del norte', el Viceministerio de Turismo a través del Plan Copesco invirtió alrededor de cuatro millones de soles en la construcción de un malecón y un paseo de madera rodeando el humedal que surgió cuando se retiró el mar producto del Fenómeno de El Niño de 1983 y $1998^{13}$ (ver figura 2). Esta inversión pública buscaba hacer de Máncora un lugar más atractivo para los turistas y, de este modo, incrementar el número de visitantes, lo cual iba a generar mayor desarrollo económico (Valenzuela, 2010). Sin embargo, poco después de inauguradas las obras, a pesar de no estar acabadas totalmente, invasores ya asentados en esta zona empezaron a tomar el terreno en el que se construyó el paseo de madera, cercando la tierra debajo del paseo y alrededor del humedal (ver la figura 3). 
Figura 2. Boceto del proyecto de inversión en el humedal de Máncora (Mincetur 2010).

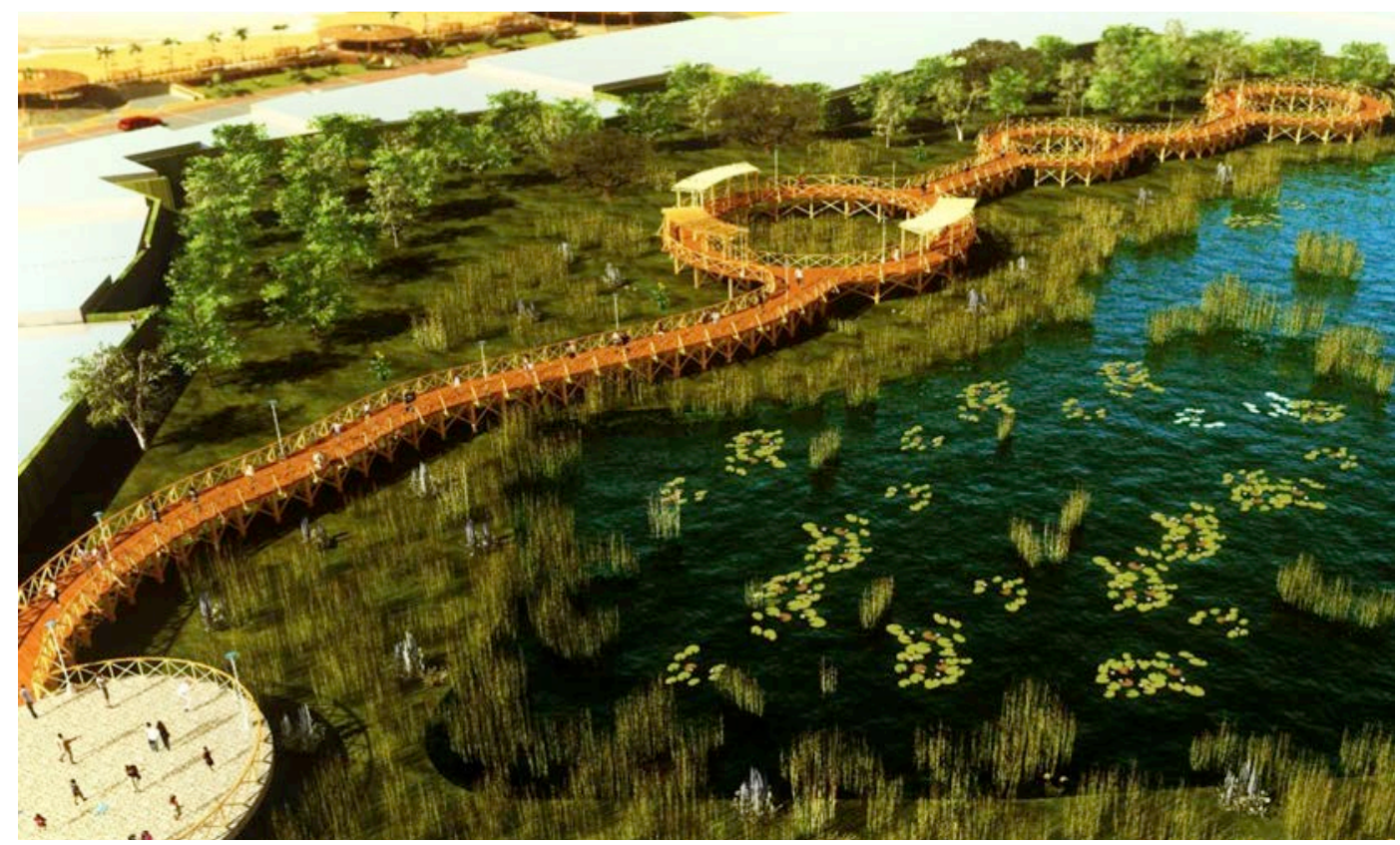

Figura 3. Invasiones en el humedal de Máncora, 2011 (foto del autor).

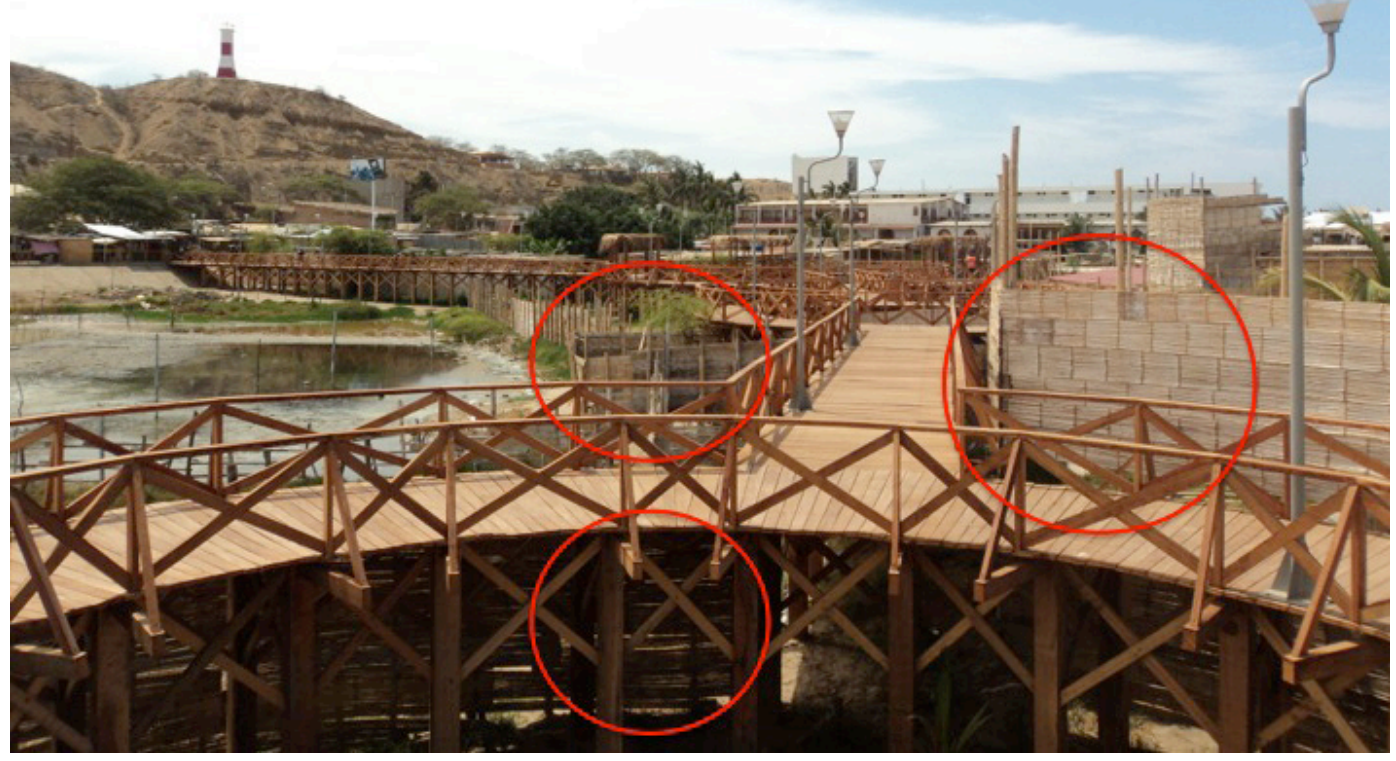


Además, si esta área no ha tenido ningún tipo de control urbano, tampoco la municipalidad ni otras instancias del Estado han invertido en servicios básicos en ella, por lo que el humedal se ha convertido en un botadero de basura y aguas servidas que se nutre de los desagües de los hoteles y restaurantes, especialmente durante la temporada alta de turistas, cuando la población del distrito se incrementa en aproximadamente seis mil personas por encima de la habitual. Todos estos factores han tenido un impacto negativo en la biodiversidad del humedal (ApecoInca, 2010), dado que se ha contaminado e invadido una zona ambientalmente frágil que se suponía iba a hacer del lugar un destino turístico más atractivo. Más aun, este humedal se ha convertido en una amenaza ambiental latente, puesto que es un foco infeccioso y fuente de enfermedades (ver la figura 4), tanto en la actualidad como también durante eventos extremos como el Fenómeno de El Niño, en los cuales las plagas y epidemias incrementan las tasas de mortalidad, poniendo en riesgo la vida de una población ya de por sí vulnerable a inundaciones y deslizamientos.

Figura 4. Degradación ambiental en el humedal de Máncora, 2011 (foto del autor).

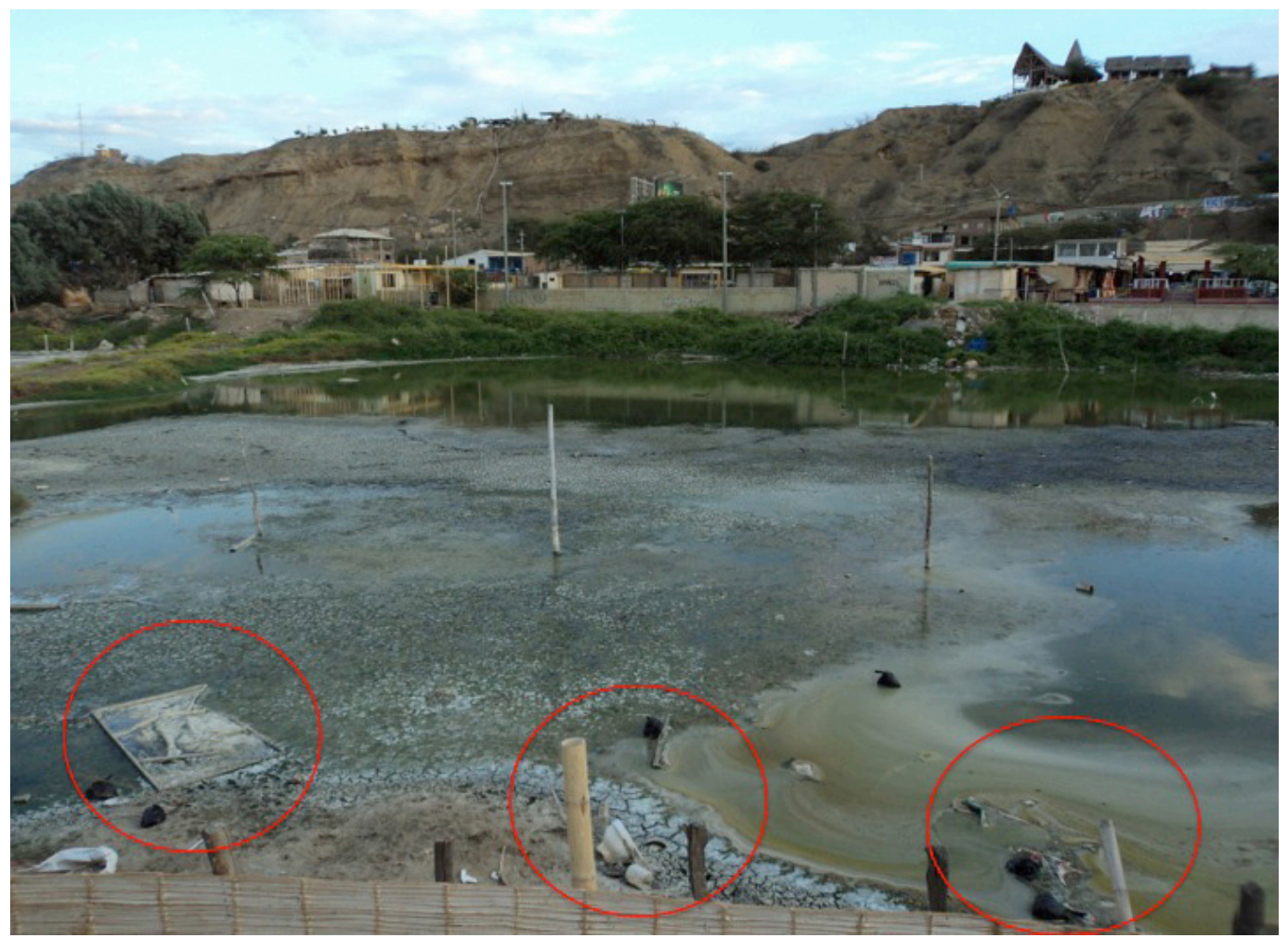

\section{Intentos por Cambiar el Modelo: Turismo, Medio Ambiente y Planificación}

En el Perú actual no se están dando cambios sustanciales en el modelo neoliberal implementado durante el gobierno de Alberto Fujimori (1990-2000) y continuado por sus predecesores (Alejandro Toledo (2001-2006), Alan García (2006-2011), Ollanta Humala (2011-2016) y Pedro Pablo Kuczinski (2016 - actualidad)). A pesar de ello, en la década de 2000, luego del gobierno autoritario de Fujimori y el retorno a la democracia, se diseñaron diversas políticas que buscaron solucionar los problemas de exclusión social en el país, redefinir el rol del Estado frente al desarrollo nacional y establecer una política ambiental nacional. 
Con el lanzamiento por las Naciones Unidas del informe conocido como reporte Brundtland, "Our Common Future", a finales de la década de 1980 (Naciones Unidas, 1987), grupos conservacionistas y ONG, lo mismo que el emprendimiento de políticas internacionales ambientales, influenciaron fuertemente para que el gobierno nacional desarrolle una agenda ambiental que permita prevenir la innegable y peligrosa degradación ambiental. En el Perú, estas acciones se manifestaron en la necesidad de crear una autoridad ambiental nacional transectorial para que pueda gobernar y articular las funciones ambientales de cada ministerio y de sus respectivas oficinas descentralizadas. Esta influencia empezó a rendir sus primeros frutos durante el año 2004, cuando el gobierno de Alejandro Toledo buscó organizar las políticas medioambientales a nivel nacional con la creación del Sistema Nacional de Gestión Ambiental (Congreso de la República, 2004). En el 2005 estos esfuerzos se intensificaron con la promulgación de la Ley general del ambiente (Congreso de la República, 2005), que buscaba diseñar el marco para implementar una regulación ambiental adecuada en el país (Lanegra, 2008). Finalmente, en 2008, se creó el Ministerio del Ambiente mediante el Decreto Legislativo ํㅜ 1013 (Congreso de la República, 2008), el cual se convirtió en la principal autoridad ambiental nacional.

Sin embargo, más que ser una prioridad para el Estado, la implementación de esta agenda ambiental fue el resultado de la presión ejercida por agentes externos producto de crisis socioambientales que surgieron con la implementación de proyectos mineros de gran envergadura. Esto explica por qué en el Perú algunos ministerios han sido prácticamente forzados a desarrollar una política ambiental, mientras que otros no la han incluido dentro de sus políticas (Lanegra, 2008). Esto es particularmente evidente en el caso de la industria turística, que se representa como 'la industria sin chimeneas' para sostener que, a diferencia de otras industrias, el turismo no genera un impacto sustancial en el medio ambiente. A nivel ministerial, a pesar de que en el organigrama del Mincetur está indicada la existencia de una Dirección de Medio Ambiente y Sostenibilidad Turística, o mejor dicho, la sección encargada de velar por el medio ambiente en contextos turísticos, este directorio aún no había sido creado en el momento en que se llevó a cabo la investigación ${ }^{14}$. Del mismo modo, desde noviembre de 2008, el "Proyecto de reglamento ambiental para el desarrollo de la actividad turística", que debe regular el impacto ambiental del turismo, no ha sido aprobado oficialmente. En otras palabras, el Perú no cuenta con una autoridad ambiental turística y esto es altamente perjudicial para las sociedades que dependen de esta actividad.

A pesar de los problemas, tensiones y dificultades alrededor de la industria turística en el Perú, en los últimos años el Estado peruano ha promulgado una serie de leyes que han tenido como finalidad fomentar su desarrollo y expansión. Si en 2002 se creó el ya mencionado Fondo para la Promoción y Desarrollo Turístico Nacional (Congreso de la República, 2002) con el objetivo de incrementar los recursos económicos para la promoción y desarrollo de infraestructura ${ }^{15}$, en 2009 la Ley general de turismo declaró esta actividad económica de interés nacional, reforzando el hecho de que el turismo juega un rol fundamental en el desarrollo del país (Congreso de la República, 2009).

Durante el periodo transcurrido entre ambas leyes, también se postuló la urgente necesidad de contar con un marco referencial de planificación. Antes de 2004, el Mincetur y sus respectivas agencias regionales tenían planes operativos regionales que no seguían necesariamente los mismos lineamientos, porque no existía un plan nacional conjunto y coordinado entre las agencias estatales, empresarios y demás actores sociales relacionados a la actividad. Esta falta de coordinación, junto con el interés del Estado en impulsar mecanismos participativos en procesos de toma de decisiones (Monge, 2006), llevó a la creación de un plan nacional único que incorporase los puntos de vista de los actores nacionales y regionales y definiera los objetivos nacionales para el turismo. Consecuentemente, financiado por el Banco Interamericano de Desarrollo (BID), el Mincetur, en coordinación con los subniveles de gobierno y el sector privado, inició en 2004 el proceso por medio del cual se creó el Pentur.

Este plan busca implementar un sistema integral de manejo turístico que promueva el desarrollo de circuitos y corredores de determinadas áreas geográficas del territorio agrupados a partir de sus características naturales, culturales y políticas. Basándose en el concepto de destino turístico, el Pentur establece los lineamientos operativos y las acciones a implementar para crear productos turísticos altamente especializados y dispersos en tres macrorregiones (norte, centro y sur) que conforman un destino turístico más general: el país, a través de la campaña llamada 'Perú, vive la leyenda' (Sariego y García, 2008: 30). El destino 'Playas del norte', que comprende las playas ubicadas en la costa de Piura y Tumbes, es uno de los siete que se priorizaron en el Pentur para desarrollar infraestructura turística. Y Máncora se escogió como punto inicial de este proyecto, puesto que ya era un destino popular, con demanda de visitantes a lo largo del año e infraestructura turística desarrollada; sin embargo, las invasiones y los crecientes conflictos sobre la tierra han hecho que el Estado deje de invertir en este destino. 
En lo que sigue, la ex viceministra de Turismo, Claudia Cornejo, explica que el Pentur es un documento que intenta cambiar la forma en que el Estado se relaciona con el desarrollo turístico a nivel local.

Fernando González: La última pregunta que te quería hacer es sobre el tema de la coordinación sobre un plan de desarrollo turístico. Se está tomando el caso de Máncora y Aguas Calientes, como mencionaste hace un momento, como los ejemplos que no se deben de repetir por el desorden o los problemas que existen, y se están tomando otros lugares desde un inicio del desarrollo. ¿Este es un intento de cambiar el modelo? ¿Tal vez tratar de coordinar el desarrollo del destino previamente a que todo este desorden se genere? Claudia Cornejo: Es que no es cambiar el modelo, yo creo que estamos ahorita aplicando el modelo [risas]. [...] Antes no ha habido modelo, simplemente las cosas sucedian y entonces en el Estado tratábamos de... [decirnos:] “Bueno, ya están allí los turistas. Entonces ¿qué podemos hacer para mejorar la situación?”. Pero entonces, en el año 2004, que es cuando se saca el primer Pentur, que es el Plan Nacional de Turismo, que luego se volvió a cambiar en el 2008 y hasta el 2018, lo que se plantea ya es la metodología de desarrollo, es decir, cómo se debe hacer el desarrollo turístico. Entonces es un tema reciente para nosotros, es un tema reciente para el Perú; la industria es una industria que está creciendo mucho, pero reciente. Entonces, al final, claro, no es que, como te digo, que se haya cambiado el modelo, lo que pasa es que ahora hay un modelo que se está aplicando. (Entrevista con Claudia Cornejo, ex directora de desarrollo turístico [2010-2011] y ex viceministra de Turismo [2011-2013]; Lima, 25 de marzo de 2011) ${ }^{16}$.

La entrevista con Claudia Cornejo refuerza mi hipótesis, que sostiene que, en vez de ser iniciativas del Estado que buscan un desarrollo turístico planificado y social, político, económica y medioambientalmente sostenible, estas reformas han sido producto de presiones externas o soluciones inmediatas implementadas en contextos de crisis. Asimismo, cuando la ex viceministra resalta: "Antes no había modelo, las cosas simplemente sucedían [...]", sus afirmaciones nos permiten entender al Pentur como un intento de cambiar el modelo turístico neoliberal implementado durante los años 1990. Este modelo, si bien no estaba definido como tal en documentos oficiales, se delineó bajo la forma de: ausencia deliberada del Estado, desigualdades de poder entre las políticas de promoción y desarrollo turístico, liberalización de los recursos naturales y ausencia de autoridades y planificación. Todo ello permitió que la industria se desarrolle bajo ciertos parámetros que fomentaron las invasiones y la expansión desordenada de infraestructura. Por ello, considero que el Estado peruano no ha jugado un rol importante en regular la expansión de la industria turística, evidenciando "una ausencia de conciencia de que el turismo, como industria, tiene impactos que no se revierten fácilmente" (Butler, 1991: 201; traducción propia).

Queda claro entonces que las políticas implementadas por el gobierno peruano, en donde la idea de límite ha estado ausente y en donde existe un desbalance entre promoción y desarrollo del turismo, están condicionadas por el enfoque de desarrollo sostenido que el geógrafo Colin Hunter (1997) ha llamado "desarrollo turístico sostenible a través del imperativo turístico". La interpretación de desarrollo sostenible que gobierna este enfoque es muy débil, ya que sus defensores buscan fomentar y expandir la industria turística a fin de satisfacer las necesidades de turistas y operadores sin importar que el destino pierda sus cualidades y que sus recursos naturales se vean afectados negativamente ${ }^{17}$. Por consiguiente, la expectativa de los actuales gobiernos y del sector empresarial sobre la cantidad de turistas que el país debe recibir es totalmente ajena a la capacidad de las poblaciones locales, el medio ambiente y los destinos turísticos en general para lidiar con las presiones que provoca el turismo masivo global y nacional. En este sentido, se puede argumentar que la industria turística en el Perú está experimentando una "falta de capacidad para determinar el nivel de crecimiento que permita lograr un desarrollo sostenible” (Butler, 1991: 201; traducción propia).

Todo esto ha contribuido fuertemente a que se produzca una expansión descontrolada de infraestructura turística en el norte del Perú, donde existen destinos que están atravesando por problemas medioambientales severos, además de desgobierno de sus recursos naturales como el del caso de Máncora. Como se explicó anteriormente, Máncora se ha expandido rápidamente sin ningún tipo de estructura de control y gobernanza de la tierra y sin un plan de manejo territorial que haya podido regular y definir los usos de la tierra y la expansión urbana. Por ello, la mayoría de las ventas de la comunidad campesina no han seguido un plan de desarrollo urbano y se ha permitido que el modelo principal de expansión urbana sea la posesión y utilización ilegal de los terrenos. Según Briassoulis, cuando estos contextos surgen, "las diferentes percepciones entre grupos tan heterogéneos y descoordinados, respecto a los costos y beneficios del uso de los recursos, resulta en su sobreexplotación y degradación" (Briassoulis, 2002: 1075; traducción propia). Consecuentemente, la presión sobre los destinos locales no preparados, y 
con servicios básicos desatendidos, se ha agravado gracias a la ausencia de planificadores y autoridades ambientales turísticas, como también de instituciones sociales que controlen la expansión del turismo.

Máncora es un claro ejemplo que nos muestra cómo la ausencia de estructuras de gobernanza de la tierra -producto de los conflictos entre autoridades locales en contextos de reforma neoliberal y expansión turística- deja vía libre para que los invasores de tierras se apropien de un lugar y se produzca el problema de libre acceso (free rider problem) (Ostrom, et al. 2002: 19), ya que no existen restricciones ni control al acceso a recursos naturales tales como la tierra y el espacio. Las invasiones traen consigo sobreuso y destrucción de los bienes turísticos comunes (tourist commons) (Healy, 1994), dado que la ausencia de "incentivos de inversión" hace que no se gaste en mejorar o controlar los recursos turísticos. Este contexto puede dar cabida a que se produzca lo que Briassoulis llama "la tragedia de los productos turísticos" (Briassoulis, 2002), especialmente si bienes comunes tales como la tierra, el agua, el aire y el paisaje (lo cual incluye los paisajes pueblerinos) experimentan problemas de sobreutilización o de ausencia de inversión. Por ello, a menos que se implementen acciones específicas, Máncora puede entrar en estado de declinación, lo cual implicaría la disminución de la demanda turística, ya que este destino sería menos atractivo (Butler, 1980).

\section{Conclusiones}

Este artículo ha resaltado las importantes debilidades del aparato estatal y de sus políticas turísticas, las cuales terminan dificultando la sostenibilidad socioeconómica y ambiental del turismo en el país. En todos los niveles hay ausencia de expertos en planificación turística y de autoridades ambientales en turismo que fiscalicen los impactos ambientales de la industria turística en espacios locales. Además, el turismo es aún considerado como una actividad que, para desarrollarse, solo necesita campañas promocionales que publiciten los destinos turísticos o que incrementen la cantidad de visitantes, pero no se entiende como una actividad que requiere planificación, control y fiscalización. Por ello, este artículo demuestra la importancia de cambiar el actual modelo de desarrollo turístico y para ello es urgente cambiar el rol del Estado en el desarrollo de los destinos.

En efecto, la implementación del modelo turístico neoliberal en el Perú reforzó lo que Ostrom et al. (1999) han llamado "régimen de acceso abierto" (open-access regime), para referirse a contextos donde los recursos naturales son utilizados sin reglas efectivas que limiten su uso y, por consiguiente, están sujetos a degradación ambiental y a la "tragedia de los bienes comunes" (Hardin, 1970) o, en contextos turísticos, a la "tragedia de los bienes turísticos comunes" (Briassoulis, 2002). El caso de Máncora muestra que el modelo de desarrollo turístico implementado en la década de 1990 provocó tensiones entre las autoridades locales que obstaculizaron la creación de mecanismos reguladores para controlar la expansión de la industria turística, permitiendo así que se legitime un patrón colonial de uso de recursos naturales que amenaza la sostenibilidad ambiental y social, y por lo tanto económica, del turismo en los espacios locales.

Por ello, esta nueva aproximación al desarrollo turístico debe poner al Estado como actor principal encargado de desarrollar la industria turística, promoviendo inversiones pero al mismo tiempo controlando la expansión de infraestructura privada en los espacios locales. Si bien se debe dar importancia a campañas promocionales que aseguren el flujo de turistas nacionales y extranjeros, también se debe controlar la demanda a partir de los límites de carga que pueden recibir los destinos locales sin que ocurran impactos socioambientales adversos que pongan en riesgo la sostenibilidad de la industria. En este sentido, es importante crear una autoridad turística ambiental y es imperante elaborar y aplicar un plan conjunto y equilibrado que incluya tanto campañas promocionales como políticas de desarrollo turístico planificado. De este modo, el Estado debe cumplir activamente un rol controlador de la expansión de la demanda y de la infraestructura turística y fiscalizar los impactos socioambientales en los destinos locales.

\section{Bibliografía}

Apecoinca, Asociación Peruana Para La Conservación De La Naturaleza-Inca

2010. "Informe No 001-2010/Apecoinca-Perú-SRCAN. Inspección ambiental del humedal de Máncora",

12 de noviembre. Sullana: Apeco. 
Baud, Michael and Annelou Ypeij (Eds.)

2009. Cultural Tourism in Latin America: The Politics of Space and Imagery. Leiden and Boston: BRILL. Briassoulis, Helen

2002. "Sustainable Tourism and the Question of the Commons". Annals of Tourism Research, vol. 29, $\mathrm{N}^{\circ}$ 4, pp. 1065-1085.

Butler, Richard

1980. "The Concept of a Tourist Area Cycle of Evolution: Implications for Management of Resources".

The Canadian Geographer, vol. 24(1): 5-12.

1991. "Tourism, Environment, and Sustainable Development". Environment Conservation, vol. 18(3): 201-209.

1998. "Sustainable Tourism: Looking Backwards in Order to Progress?" En Hall Michael y Alan Lew (Eds.). Sustainable Tourism: A Geographical Perspective. Essex: Addison Wesley Longman Limited, pp. 25-34.

1999. "Sustainable Tourism: A State-of-the-art Review". Tourism Geographies: An International Journal of Tourism Space, Place and Environment, 1(1): 7-25.

Carnaffan, Jane

2010. "Peru: Land of the Incas? Development and Culture in Responsible, Homestay Tourism in Peru".

Tesis Doctoral (PhD). Newcastle University.

Cohen, Erick

1979. "Rethinking the Sociology of Tourism". Annals of Tourism Research, 6(1): 18-35.

Congreso de la República

1991. Decreto Legislativo $N^{\circ}$ 653. Aprueba la Ley de promoción de las inversiones en el sector agrario, 7 de enero.

1995. Ley $N^{\circ}$ 26505. Ley de la inversión privada en el desarrollo de las actividades económicas en las tierras del territorio nacional y de las comunidades campesinas y nativas, 14 de julio.

1997. Ley $N^{\circ}$ 26845. Ley de titulación de comunidades campesinas de la costa, 23 de julio.

2002. Ley $N^{\circ}$ 27889. Ley que crea el fondo y el impuesto extraordinario para la promoción y desarrollo turístico nacional. 18 de diciembre.

2004. Ley $N^{\circ}$ 28245. Ley marco del Sistema Nacional de Gestión Ambiental, 4 de junio.

2005. Ley $N^{\circ}$ 28611. Ley general del ambiente, 13 de octubre.

2008. Decreto Legislativo $N^{\circ} 1013$. Decreto legislativo que aprueba la Ley de creación, organización y funciones del Ministerio del Ambiente, 13 de mayo.

2009. Ley $N^{\circ}$ 29408. Ley general de turismo, 17 de setiembre.

Desforges, Luke

2000. "State Tourism Institutions and Neo-liberal Development: A Case Study of Peru". Tourism Geographies, 2(2): 177-192.

EL COMERCIO

2012. "El turismo puede ser la segunda actividad generadora de divisas". El Comercio, 19 de junio. Consulta: 20 de junio de 2012. <http://elcomercio.pe/turismo/1430609/noticia-turismo-puede-segunda-actividad-generadora-divisas $>$

Fuller, Norma

2010. "Lunahuaná, un destino turístico. Transformaciones en la composición social, economía familiar y relaciones de género". Pasos, 8(2): 293-304.

García, Pablo

2015. In the Name of the Tourist: Landscape, Heritage, and Social Change in Chinchero. Tesis Doctoral (PhD). St. Andrews University.

Gascón, Jorge

2005. Gringos como en sueños: Diferenciación y conflicto campesinos en los Andes Peruanos ante el desarrollo del turismo. Lima: IEP.

Hardin, Garrett

1970. "The Tragedy of the Commons". En Love, Glen A. y Rhoda M. Love (Eds.). Ecological Crisis:

Readings for Survival. Nueva York, Chicago, San Francisco y Atlanta: Harcourt Brace Jovanovich.

Healy, Robert

1994. "The 'Common Pool' Problem in Tourism Landscapes". Annals of Tourism Research, 21(3): 596-611. Hunter, Colin

1997. "Sustainable Tourism as an Adaptive Paradigm". Annals of Tourism Research, 24 (4): 850-867. 
INEI, INSTITUTO NACIONAL DE ESTADÍSTICA E INFORMÁTICA

2007. Censos nacionales 2007. XI de población y VI de vivienda. Lima: INEI.

Lanegra, Iván

2008. El (ausente) Estado ambiental: razones para la reforma de las instituciones y las organizaciones públicas ambientales en el Perú. Lima: CDE.

MINCETUR

2010. "Producto turístico Máncora" [PPT]. Lima: Mincetur.

2012. "Perú: ingreso trimestral de divisas generado por el turismo receptivo, 2002-2011". Mincetur.

Consulta: 30 de julio de 2012. <http://www.mincetur.gob.pe/newweb/portals/0/turismo/PERU_Ingr_

Trim_Divisas_2002_2011.pdf>

Monge, Carlos

2006. Decentralisation: An Opportunity for Democratic Governance. En Crabtree, John. (Ed.). Making

Institutions Work in Peru. Londres: Institute for the Study of the Americas, pp. 45-65.

NACIONES UNIDAS

1987. "Report of the World Commission on Environment and Development. Our Common Future".

Naciones Unidas. Consulta: 7 de julio de 2015.<http://www.un-documents.net/our-common-future.pdf> Ostrom, Elinor, Joanna Burger; Christopher Field; Richard Norgaard and David Policansky (Eds.)

1999. "Revisiting the Commons: Local Lessons, Global Challenges". Sciences. 284: 278-282.

Ostrom, Elinor; Thomas Dietz; Neves Dolsak; Paul C. Stern; Susan Stonich y Elke U. Weber (Eds.)

2002. The Dramma of the Commons. Washington, DC: National Academy Press.

Pálsson, Gisli

1996. "Human-environmental Relations: Orientalism, Paternalism and Communalism". En Descola,

Philippe y Gisli Pálsson, (Eds.) Nature and Society: Anthropological Perspective. London and New

York: Routledge.

Pineda-Zumaran, Jessica

2012. "The Evolution of Peruvian Policy and Planning Thinking and its Influence in the Built-up

Environment of Cities". Ponencia en Symposium UK Postgraduate Research on Peru, 3 de mayo.

Newcastle University.

PROMPERÚ

2009. "Vive la leyenda: construyendo experiencias". Lima: PromPerú. Consulta: 16 de agosto de 2012. $<$ http://media.peru.info/issuu/construyendoexp.pdf >

Raftoupolous, Malayna

2013. Questioning the Principles of Sustainable Tourism Development: A Case Study of Cocachimba, RPP

Peru. Tesis Doctoral (PhD). University of Liverpool, Liverpool.

2014. "Asesinan a una persona en el sector oeste de Piura". RPP, 26 de agosto. Consulta: 22 de junio de 2015. <http://www.rpp.com.pe/2014-08-26-asesinan-a-hombre-de-55-anos-en-el-sector-oeste-de-piura-noticia_719844.html>

Saarinen, Jarkko

2006 "Traditions of Sustainability in Tourism Studies". En Annals of Tourism Research, 33(4): 1121-1140.

Sariego, Ignacio y Carlos García

2008. Pentur [2008-2018]: síntesis para la puesta en operación. Lima: Ministerio de Comercio Exterior y Turismo.

Valenzuela, Fernando

2010. "Destino turístico Playas del Norte. Estudio de rentabilidad social de las inversiones en turismo".

En: MINCETUR. Destinos turísticos. Estudios de rentabilidad social de las inversiones en turismo [disco compacto]. Lima: Mincetur.

VICEMINISTERIO DE TURISMO-MINCETUR

2009. "Playas del norte. Destinos turísticos 2010-2011". Lima: Mincetur.

2010. "Organigrama VMT". Viceministerio de Turismo. Mincetur. <http://www.mincetur.gob.pe/newweb/

Default.aspx?tabid $=4200>$

Woodman, Ronand y Antonio Mabres

1993. "Formación de un Cordón Litoral en Máncora, Perú, a Raíz De El Niño de 1983". Bull. Inst. fr. études andines, 22(1): 213-226.

Ypeij, Annelou y Annelies Zoomers (Eds.)

2006. La Ruta Andina: Turismo y Desarrollo Sostenible en Perú y Bolivia. Quito-Ecuador: Abya Yala, CBC, CEDLA, IEP. 
Zorn, Elayne y Linda Clare Forthing

2007. "Communitarian Tourism Hosts and Mediators in Peru". Annals of Tourism Research, 34(3): 673-689.

\section{Notas}

1 El año 2002 la industria turística nutrió a la economía nacional con 837 millones de dólares americanos. El 2011 este monto se incrementó exponencialmente a 2,912 millones de dólares (Mincetur, 2012). Además, estadísticas recientes muestran que en 2007 el turismo contribuyó en un 4\% al producto bruto interno (PBI) del país.

2 En 2007, la población del distrito de Máncora era de 10,547 habitantes (INEI, 2007), los cuales dependen directa o indirectamente del turismo (según autoridades locales, el 90\% de los pobladores están de alguna manera relacionados al turismo) y la pesca artesanal.

3 Comisión de Promoción del Perú para la Exportación y el Turismo.

4 Ejemplos de estas campañas son: "El norte pone", "La selva pone" y "Cusco pone".

5 Entrevista con Mercedes Araoz, ex ministra de Comercio Exterior y Turismo (2006 - 2009) y actual Vice-Presidenta del Perú (2016 - actualidad); Lima, 12 de abril de 2011.

6 Como opina Carlos Canales, ex presidente de Canatur (entrevista realizada en Lima, 31 de marzo de 2011).

7 Actualmente, el directorio de PromPerú está constituido por nueve miembros del sector público y cuatro del sector privado.

8 En la actualidad esta es una subdirección del Viceministerio de Turismo.

9 El Viceministerio de Turismo es el responsable de liderar el desarrollo turístico a nivel nacional.

10 Entre los paradigmas que condicionan la relación naturaleza - sociedad identificados por Pálsson (1996), el paradigma colonial supone que la naturaleza es una esfera separada de la sociedad que debe ser conquistada, domesticada, explotada y manejada para satisfacer las necesidades humanas de producción, consumo y explotación industrial.

11 Entrevista con Florencio Olibos, ex alcalde de Máncora; Máncora, 6 de noviembre de 2010.

12 Comentario de Everardo Távara, ex presidente de la Comunidad Campesina de Máncora (entrevista realizada en Máncora, 18 de diciembre de 2010).

13 Ver Woodman and Mabres (1993).

14 Lanegra ya había notado que para el año 2008 el directorio no estaba creado (Lanegra 2008: 105) y, de acuerdo al organigrama del Viceministerio de Turismo, ni se ha incluido hasta ahora (Viceministerio de Turismo-Mincetur 2010).

15 Estudios gubernamentales han mostrado que los fondos públicos para el turismo se han incrementado dramáticamente desde 2003 (Valenzuela 2010: 30).

16 Resaltado del autor.

17 Esta aproximación difiere de otros enfoques que sí han tomado en cuenta los impactos medioambientales del turismo (ver Hunter 1997). 